3. Bezborodov Yu. G., Khozhanov N. N., Auganbaeva Zh. S. Evaluation of the productivity of ameliorative agricultural landscapes of the Zhambyl region // Prirodoobustroystvo. 2020. No. 4. P. 22-27.

4. Borodychev V. V., Lytov M. N. Algorithm for solving problems of managing the water regime of the soil during irrigation of agricultural crops // Melioration and water management. 2015. No. 1. P. 8-11.

5. Optimal irrigation control based on modern computational algorithms / V. V. Borodychev [et al.] // Bulletin of the Nizhnevolzhsky agro-university complex: science and higher professional education. 2015. No. 4 (40). P. 21-28.

6. Khozhanov N. N., Tursynbaev Kh. I. Methodology for calculating the irrigation rate for agricultural crops // The Scientific Heritage. 2021. No. 59. P. 51-54.

7. Khozhanov N. N., Erzhanova N. K. Optimization of the irrigation rate of agricultural crops // Water management of Kazakhstan. 2012. No. 8-9 (46-47).

8. Khozhanov N. N., Tursynbaev Kh. I. Energy concepts for the development of a farming system. Bulletin of the Mountain State University. 2018. No. 55 (part 1). P. 20-26.

9. Shtanko A. S., Shkura V. N. Methodology for calculating irrigation rates that ensure the formation of specified parameters of soil moisture during drip irrigation // Scientific journal of the Russian Research Institute of Melioration Problems. 2018. No 4 (32). P. 60-76. http: www.rosniipmsm.ru/archi-ve? $\mathrm{N}=567 \&$ id $=571$.

10. Akhmedov A. D., Dzhamaletdinova E. E., Zasimov A. E. Water-saving irrigation regimes for vegetable crop production under conditions of Volga-Don interfluve // RUDN journal of Agronomy and animal industries. 2018. V. 13. No 3. P. 185-193.

11. Akhmedov A. D., Borovoy E. P., Khodiakov E. A. Water-saving technologies for vegetables in the south of Russia // IOP Conf. Series: Earth and Environmen-tal Science: Conference on Innovations in Agricultural and Rural development. 2019. V. 341. 012105.

12. Khodiakov E. Management of the water regime of soil to increase the vegetable crops yield with different irrigation methods in the south of Russia // E3S Web Conf. International Conference: Ensuring Food Security in the Context of the COVID-19 Pandemic (EFSC2021). 2021. Volume 282.

13. Khozhanov N. N., Tursunbayev Kh. Metodology for calculaming the irrigation rate jf agricultural crops // The scientific heritage. 2021. V. 1. № 59.

14. Optimum control model of soil water regime under irrigation // A. S. Ovchinnikov, V. V. Borodychev, M. N. Lytov, V. S. Bocharnikov, S. D. Fomin, O. V. Bocharnikova, E. S. Vorontsova // Bulgarian journal of agricultural Science. 2018. № 24 (5). P. 909-913.

\title{
Author's Information
}

Khozhanov Nietbay Nurzhanovich, Candidate of Agricultural Sciences, Senior Researcher, Associate Professor of the Department of Melioration and Agronomy, Taraz Regional University named after M.Kh.Dulati, Taraz, Republic of Kazakhstan. khozhanov55 @ mail.ru

\section{Информация об авторе}

Хожанов Ниетбай Нуржанович, кандидат сельскохозяйственных наук, старший научный сотрудник, доцент кафедры «Мелиорация и агрономия» Таразского регионального университета имени М.Х.Дулати (г. Тараз, Республика Казахстан).

khozhanov55@mail.ru

\section{DOI: 10.32786/2071-9485-2021-03-18 \\ EVALUATION OF THE QUALITY OF THE NATURAL ENVIRONMENT BY FLUCTUATING ASYMMETRY OF LEAF BLADES OF SMALL-LEAVED ELM(ULMUS PUMILA L.) IN THE SETTLEMENT «OKTYABRSKY» OF KALACHEVSKY DISTRICT OF THE VOLGOGRAD REGION}

\author{
L.S. Panchenko \\ Volgograd State Technical University, Volgograd
}

Received 09.04.2021

Submitted 30.08.2021

\section{Summary}

The article is devoted to the assessment of the quality of the natural environment by the method of fluctuating asymmetry of leaf blades of small-leaved elm (Ulmus pumila L.) in the in the settlement «Oktyabrsky» of the Kalachevsky district of the Volgograd region. The analysis of the de- 
velopmental stability of small-leaved elm (Ulmus pumila L.) in the settlement «Oktyabrsky» in comparison with the control area of the village «Buzinovka» of the Kalachevsky district of the Volgograd region. The issues of the environmental impact of the quality of the natural environment on the yield of agricultural crops are highlighted. The reasons for the unsatisfactory assessment of the quality of the natural environment in the settlement «Oktyabrsky» are indicated.

Abstract
Introduction. The relevance of this work lies in the fact that studies of the quality of the natural environment in the settlement «Oktyabrsky» of the Kalachevsky District of the Volgograd Region, have not been previously conducted. Residents live on the territory of this settlement, a kindergarten, a school, a clinic and military units are located. Fields of a farm where cereals are grown are adjacent to the settlement. The aim of the study was to assess the quality of the natural environment based on the fluctuating asymmetry of leaf blades of the small-leaved elm (Ulmus pumila L.) in the settlement «Oktyabrsky», as well as to analyze the factors that negatively affect the quality of the natural environment in the village with the aim of their further elimination. Object. The object of the study was the leaf blades of the small-leaved elm (Ulmus pumila L.). Materials and methods. The material of the study was the collection of the leaves of the smallleaved Elm (Ulmus pumila L.), carried out at the end of September 2020 in two settlements of the Kalachevsky district of the Volgograd region: the settlement «Oktyabrsky» and the village «Buzinovka». The natural environment of these villages differs in terms of the level of anthropogenic impact, therefore, the natural environment of the village «Buzinovka» was assessed as a control one. The assessment of the quality of the natural environment by the fluctuating asymmetry of the leaf blades of the small-leaved elm (Ulmus pumila L.) was carried out according to the method of V.M. Zakharova (1986). Results and conclusions. As a result of the research, the nature of the fluctuating asymmetry of the leaf blades of the small-leaved elm (Ulmus pumila L.) in the territories of the settlement «Oktyabrsky» and the village «Buzinovka» of the Kalachevsky district of the Volgograd region. It was found that on the control plot of the territory of the village "Buzinovka», the integral index of fluctuating asymmetry of leaf blades of small-leaved elm (Ulmus pumila L.) is 0.033 , which, in accordance with the table compiled by V.M. Zakharov (2000), is considered a conditional norm and is observed in samples of leaf blades of plants growing in favorable natural conditions. A higher value of the integral index of fluctuating asymmetry of leaf blades of small-leaved elm (Ulmus pumila L.) was determined in the investigated territory of the settlement «Oktyabrsky». This value is 0.127 , which, according to the table compiled by V.M. Zakharov, is assessed as critical. Such values of fluctuating asymmetry of leaf blades are characteristic of plants growing in extremely unfavorable conditions. At the same time, the plants are in a depressed state. Comparison of integral indicators of fluctuating asymmetry of leaf blades of small-leaved elm (Ulmus pumila L.) of two study sites made it possible to establish significant differences, expressed in an increase in this indicator by 3.8 times in the settlement «Oktyabrsky» as compared with the village «Buzinovka». Thus, using the method of fluctuating asymmetry of leaf blades of small-leaved elm (Ulmus pumila L.), the state of the natural environment in the settlement «Oktyabrsky» was characterized as critical, which is associated with a high anthropogenic load.

Key words: bioindication, bioindicators, fluctuating asymmetry, bilateral symmetry, developmental stability, morphogenetic homeostasis, phenotypic variability.

Citation. Panchenko L. S. Evaluation of the quality of the natural environment by fluctuating asymmetry of leaf blades of small-leaved elm (Ulmus Pumila L.) in the settlement «Oktyabrsky» of Kalachevsky district of the Volgograd region. Proc. of the Lower Volga Agro-University Comp. 2021. 3 (63). 181-190 (in Russian). DOI: 10.32786/2071-9485-2021-03-18.

Conflict of interest. The author declares no conflicts of interest. 


\title{
ОЦЕНКА КАЧЕСТВА ПРИРОДНОЙ СРЕДЫ ПО ФЛУКТУИРУЮЩЕЙ АСИММЕТРИИ ЛИСТОВЫХ ПЛАСТИНОК ВЯЗА МЕЛКОЛИСТНОГО (ULMUS PUMILA L.) В П. ОКТЯБРЬСКИЙ КАЛАЧЕВСКОГО РАЙОНА ВОЛГОГРАДСКОЙ ОБЛАСТИ
}

\author{
Л. С. Панченко, стариий преподаватель
}

Волгоградский государственный технический университет, г. Волгоград.

Received 09.04.2021

Submitted 30.08.2021

Актуальность. Актуальность данной работы заключается в том, что исследования качества природной среды в п. Октябрьский Калачевского района Волгоградской области ранее не проводились. На территории этого поселка проживают жители, расположены детский сад, школа, поликлиника и воинские части. Вплотную к поселку примыкают поля фермерского хозяйства, на которых выращивают злаковые культуры. Цель. Целью исследования являлась оценка качества природной среды по флуктуирующей асимметрии листовых пластинок вяза мелколистного (Ulmus pumila L.) в п. Октябрьский, а также анализ факторов, негативно влияющих на качество природной среды в поселке, с целью их дальнейшего устранения. Объект. Объектом исследования являлись листовые пластинки вяза мелколистного (Ulmus pumila L.). Материалы и методы. Материалом исследования явились сборы листьев вяза мелколистного (Ulmus pumila L.), проведенные в конце сентября 2020 года в двух населённых пунктах Калачевского района Волгоградской области: п. Октябрьский и с. Бузиновка. Природная среда этих посёлков различается по уровню антропогенного воздействия, поэтому природная среда с. Бузиновка оценивалась в качестве контрольной. Оценка качества природной среды по флуктуирующей асимметрии листовых пластинок вяза мелколистного (Ulmus pumila L.) проведена по методике B.M. Захарова (1986). Результаты и выводы. В результате проведенных исследований изучен характер флуктуирующей асимметрии листовых пластинок вяза мелколистного (Ulmus pumila L.) на территориях п. Октябрьский и с. Бузиновка Калачевского района Волгоградской области. Установлено, что на контрольном участке территории с. Бузиновка интегральный показатель флуктуирующей асимметрии листовых пластинок вяза мелколистного (Ulmus pumila L.) составляет 0,033 , что в соответствии с таблицей, составленной В.M. Захаровым (2000), считается условной нормой и наблюдается в выборках листовых пластинок растений, произрастающих в благоприятных природных условиях. Более высокая величина интегрального показателя флуктуирующей асимметрии листовых пластинок Вяза мелколистного (Ulmus pumila L.) определена на исследованной территории п. Октябрьский. Эта величина составляет 0,127 , что согласно таблице, составленной В.М. Захаровым, оценивается как критическое значение. Такие величины флуктуирующей асимметрии листовых пластинок характерны для растений, произрастающих в крайне неблагоприятных условиях. При этом растения находятся в угнетённом состоянии. Сопоставление интегральных показателей флуктуирующей асимметрии листовых пластинок вяза мелколистного (Ulmus pumila L.) двух мест исследования позволило установить достоверные различия, выраженные в увеличении этого показателя в 3,8 раза в п. Октябрьский по сравнению с с. Бузиновка. Таким образом, методом флуктуирующей асимметрии листовых пластинок вяза мелколистного (Ulmus pumila L.) охарактеризовано состояние природной среды в п. Октябрьский как критическое, что связано с высокой антропогенной нагрузкой.

Ключевые слова: биоиндикация, биоиндикаторы, флуктуирующая асимметрия, билатеральная симметрия, экосистемы, фитоценозы.

Цитирование. Панченко Л. С. Оценка качества природной среды по флуктуирующей асимметрии листовых пластинок Вяза мелколистного (Ulmus pumila L.) в п. Октябрьский Калачевского района Волгоградской области. Известия НВ АУК. 2021. 3(63). 181-190. DOI: 10.32786/2071-9485-2021-03-18.

Конфликт интересов. Автор заявляет об отсутствии конфликта интересов. 
Введение. В последнее время общество чаще и полнее использует в своей деятельности сведения о качестве природной среды. Эта информация необходима в повседневной жизни людей для сохранения здоровья, ведения промышленного и сельского хозяйства, для контроля природных явлений. Для выявления изменений в природе возникла необходимость в постоянном наблюдении за её состоянием. Необходимость в экологическом мониторинге возникла в связи с ухудшением качества природной среды в национальном и международном масштабах. Цель экологического мониторинга: информационное обеспечение управления природоохранной деятельностью и экологической безопасностью. Для оценки и прогнозирования экологического состояния природной среды, наряду с другими методами, широко используется биологический мониторинг. Биологический мониторинг является наиболее надежным, так как биоиндикаторы - это природные индикаторы, которые в процессе длительного эволюционного развития приобрели способность адаптироваться к определенному состоянию экологических систем. Малейшие изменения в звеньях сложных цепей экологических систем в природе приводят к изменениям в структуре и физиологии биоиндикаторов, которые фиксируются доступными способами. В. М. Захаров считает, что среди биоиндикаторов растения объективнее фиксируют изменения, происходящие в природе, по сравнению с животными, так как они одновременно поглощают вещества из воздуха для фотосинтеза и из почвы в процессе питания [1]. Известный американский ученый Ю. Одум считал, что древесные растения являются более точными биоиндикаторами, чем травянистые растения. Это связано, по его мнению, с тем, что физиологические процессы в травянистых растениях протекают быстрее, чем в древесных растениях, поэтому по исследованиям состояния мелких растительных объектов нельзя объективно оценить качество природной среды за длительный промежуток времени [1]. С. Ю. Шаркова и Е. В. Надежкина указывают на то, что по качественным изменениям листьев древесных растений можно сделать анализ экологического состояния природной среды городов и поселков городского типа. Они считают, что индикатором для первичной оценки загрязнения фитоценозов кислотными выбросами может служить асимметрия пластинок листьев широколиственных пород деревьев. Флуктуирующая асимметрия листовой пластинки является незначительным отклонением от её билатеральной симметрии под воздействием изменившихся факторов природной среды. Билатеральная симметрия - это «симметрия листка», т.е. симметрия с одной плоскостью. Этот вид симметрии возник в процессе эволюционного развития природы у организмов и органов, которые растут и передвигаются горизонтально и наклонно по отношению к земной поверхности. При изменении условий природной среды происходит нарушение билатеральной симметрии листьев растений асимметрия. Незначительные отклонения от билатеральной симметрии листовой пластинки представляют собой флуктуирующую асимметрию. Показатели флуктуирующей асимметрии листовых пластинок растений позволяют сделать анализ экологического состояния исследуемой территории. Метод оценки качества природной среды по показателям флуктуирующей асимметрии листовых пластинок растений на данный момент является приоритетным, так как не требует больших финансовых затрат при его использовании и анализе, а также является достаточно достоверным.

Сельское хозяйство - один из древнейших и распространенных видов человеческой деятельности. Экологические факторы природной среды оказывают непосредственное влияние на качественные и количественные показатели урожая. Они могут оказывать отрицательное воздействие на качество урожая возделываемых человеком сельскохозяйственных культур в условиях интенсивной урбанизации и загрязняющего воздействия сельскохозяйственного производства на окружающую среду. В этих условиях необходима оценка качества природной среды комплексом методов, среди которых первостепенное значение отводится биоиндикации. 
Материалы и методы. Материалом исследования стали сборы листьев вяза мелколистного (Ulmus pumila L.), проведенные в конце сентября 2020 года в двух населенных пунктах Калачевского района Волгоградской области: с. Бузиновка и п. Октябрьский, которые различаются по уровню антропогенного воздействия на состояние природной среды. Места исследования удалены друг от друга на расстояние около 25 км (рисунок 1).

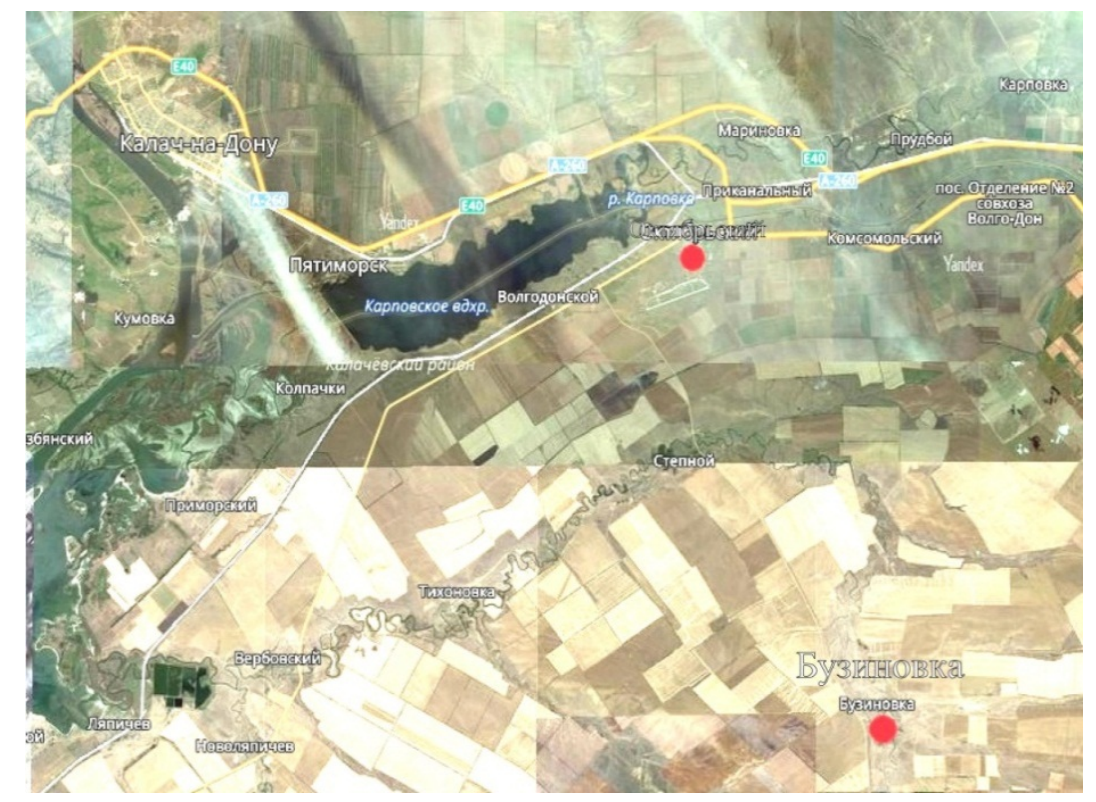

Рисунок 1 - Географическое положение мест исследования

Figure 1 - Geographical location of the study sites

Бузиновка - село в Калачевском районе, административный центр Бузиновского сельского поселения. Основан в XIX веке как поселок Царицынский. Протяженность с запада на восток составляет 2 км 664 м. Село расположено в 55 километрах от г. Калачна-Дону. Село расположено в степной зоне. Распространены каштановые почвы.

Климат засушливый. Среди древесной растительности распространен вяз мелколистный (Ulmus pumila L.), лиственное дерево семейства вязовых.

Рядом с селом протекает река Донская Царица, которая является левым притоком Дона. Длина реки Донская Царица на протяжении Бузиновского административного центра составляет 15,6 км. Берега в селе пустынные, за селом озеленены рогозом мелколистным.

На территории этого села расположены поля, зернохранилища и сельскохозяйственная техника нескольких мелких крестьянско-фермерских хозяйств. Село удалено от промышленных предприятий, крупных автомагистралей.

Октябрьский - поселок городского типа Калачевского района Волгоградской области, военный городок гарнизона Мариновка. Рядом находится шлюз ВолгоДонского канала, ветка железнодорожного пути Карповская - Ложки, рядом с поселком проходит автомобильная дорога областного значения.

На территории п. Октябрьский находится военный аэродром, т.к. она является учебной базой летных училищ.

Вяз мелколистный, или приземистый (Ulmus pumila L.) - лиственное дерево, вид рода вяз (Ulmus), семейства вязовые (Ulmacease). Средняя продолжительность жизни вяза мелколистного (Ulmus pumila L.) составляет 35-55 лет. Этот вид древесной растительности за указанный промежуток времени вырастает до немалых размеров. 
Вяз мелколистный (Ulmus pumila L.) является господствующим среди древеснокустарниковых насаждений на исследуемых территориях. Средний возраст деревьев составляет 10-15 лет. Средняя высота деревьев - 7-12 метров. На 1 га произрастает в среднем до 30 деревьев.

В ходе исследования использовала различные методы: сбор материала, измерение метрических признаков, изучение флуктуирующей асимметрии и вычисление показателей асимметрии, статистическую обработку материала.

Листья вяза мелколистного (Ulmus pumila L.) собирала в конце сентября 2020 года после завершения их интенсивного роста. Для исследования были отобраны деревья среднего возраста. Листья собирала с десяти деревьев, расположенных близко друг от друга. С каждого дерева собирала по десять листьев. Всего с одной площадки было собрано сто листьев. Для сбора листьев использовала только нижнюю часть кроны, с которой отбирала листья средних размеров.

Для оценки стабильности развития вяза мелколистного (Ulmus pumila L.) были определены размеры листовых пластинок. Для каждой листовой пластинки $(\mathrm{i}=1,2 \ldots \mathrm{n}$, номер листа) брала промеры 5-ти стандартных метрических билатеральных признаков $(\mathrm{j}=1,2 \ldots \mathrm{m}$, номер признака): ширина листа (первый показатель); длина второй жилки второго порядка (второй показатель); расстояние между основаниями второй и третьей жилок второго порядка (третий показатель); расстояние между вершинами второй и третьей жилок второго порядка (четвертый показатель); угол между центральной и второй жилками второго порядка (пятый показатель) (рисунок 2).

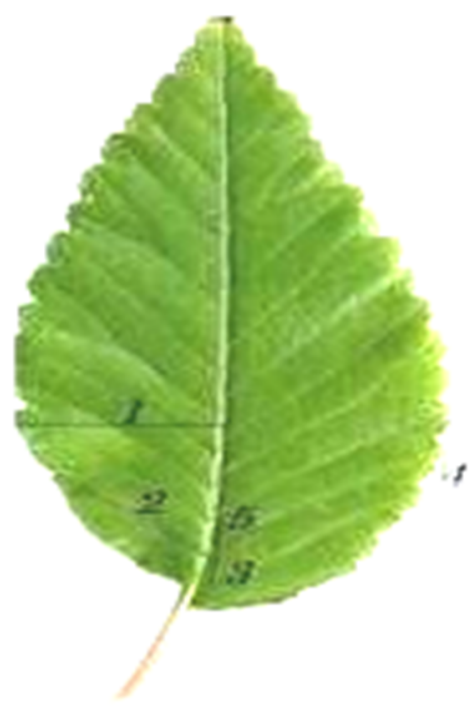

Рисунок 2 - Схема морфологических признаков, использованных для оценки стабильности развития вяза мелколистного (Ulmus pumila L.):

1 - ширина листа; 2 - длина второй жилки второго порядка;

3 - расстояние между основаниями второй и третьей жилок второго порядка;

4 - расстояние между вершинами второй и третьей жилок второго порядка; 5 - угол между центральной и второй жилками второго порядка

Figure 2 - Scheme of morphological features used to asses the stability of the development of small leaved Elm (Ulmus pumila L.):

1 - sheet width; 2 - the length of the second vein of the second order;

3 - the distance between the bases of the second and third veins of the second order;

4 - the distance between the vertices of the second and third veins of the second order;

5 - the angle between the central and second veins of the second oeder 
Промеры производились с правой и левой сторон листовой пластинки. Промеры выполняла линейкой с точностью до 0,5 мм. Угол между жилками измеряла транспортиром. Интерес представляют не абсолютные показатели, а разница между ними справа и слева.

Статистическую значимость различий между выборками по величине интегрального показателя стабильности развития определяла по критерию Стьюдента.

Результаты и обсуждение. Достоверным и простым методом оценки состояния окружающей среды является определение стабильности развития живых организмов, которая показывает способность организмов к минимизации случайных нарушений развития.

Оценка природной среды на территории с. Бузиновка и п. Октябрьский проведена по состоянию листьев наиболее распространённого на этих территориях древесного растения вяза мелколистного (Ulmus pumila L.). Используя методику флуктуирующей асимметрии, определяла характер изменчивости 5-ти билатеральных признаков: ширина листа, длина второй жилки второго порядка, расстояние между основаниями второй и третьей жилок второго порядка, расстояние между вершинами второй и третьей жилок второго порядка, угол между центральной и второй жилками второго порядка.

Как видно из таблицы 1 , изучение изменчивости листьев вяза мелколистного (Ulmus pumila L.) выявило нарушение симметрии билатеральных признаков. Степень асимметрии признаков разная. Наиболее выражена асимметрия в расстоянии между основаниями второй и третьей жилок второго порядка, в расстоянии между вершинами этих жилок. Минимальная асимметрия у пятого показателя - угла между центральной и второй жилкой второго порядка. Сравнение средних значений асимметрии листьев вяза мелколистного (Ulmus pumila L.) выявило различия между растениями исследуемых территорий. По 3-м признакам: ширине листа, расстоянию между основаниями второй и третьей жилок второго порядка, углу между центральной и второй жилками второго порядка - асимметрия достоверно выше у листьев вяза мелколистного (Ulmus pumila L.) в п. Октябрьский.

Таблица 1 - Показатели стабильности развития вяза мелколистного (Ulmus pumila L.) по пяти признакам в местах исследования

Table 1 - Indicators of the stability of the development of small - leaved Elm (Ulmus pumila L.) by signs in study sites

\begin{tabular}{|c|c|c|c|c|c|c|}
\hline $\begin{array}{c}\text { Места исследо- } \\
\text { вания / } \\
\text { Research sites }\end{array}$ & $\begin{array}{l}\text { Показатель/ } \\
\text { Indicator }\end{array}$ & $\begin{array}{l}1 \text { при- } \\
\text { знак / } \\
1 \text { sign } \\
\end{array}$ & $\begin{array}{l}2 \text { при- } \\
\text { знак / } \\
2 \text { sign } \\
\end{array}$ & $\begin{array}{l}3 \text { при- } \\
\text { знак / } \\
3 \text { sign } \\
\end{array}$ & $\begin{array}{l}4 \text { при- } \\
\text { знак / } \\
4 \text { sign } \\
\end{array}$ & $\begin{array}{l}5 \text { при- } \\
\text { знак / } \\
5 \text { sign } \\
\end{array}$ \\
\hline \multirow[t]{2}{*}{$\begin{array}{l}\text { с. Бузи- } \\
\text { новка / s. Buzi- } \\
\text { novka }\end{array}$} & $\begin{array}{l}\text { Средняя частота прояв- } \\
\text { ления асимметрии при- } \\
\text { знака / Average frequen- } \\
\text { cy of occurrence of fea- } \\
\text { ture asymmetry }\end{array}$ & $\begin{array}{l}0,0197 \\
\pm 0,005\end{array}$ & $\begin{array}{l}0,0250 \\
\pm 0,016\end{array}$ & $\begin{array}{l}0,0442 \\
\pm 0,004\end{array}$ & $\begin{array}{l}0,0273 \\
\pm 0,084\end{array}$ & $\begin{array}{l}0,0086 \\
\pm 0,007\end{array}$ \\
\hline & $\begin{array}{l}\text { Интегральный показа- } \\
\text { тель / Integral indicator }\end{array}$ & 0,01968 & 0,0245 & 0,04417 & 0,02731 & 0,00858 \\
\hline \multirow[t]{3}{*}{$\begin{array}{l}\text { п. Октябрь- } \\
\text { ский / } \\
\text { p. Oktyabr- } \\
\text { sky }\end{array}$} & $\begin{array}{l}\text { Средняя частота прояв- } \\
\text { ления асимметрии при- } \\
\text { знака / Average frequen- } \\
\text { cy of occurrence of fea- } \\
\text { ture asymmetry }\end{array}$ & $\begin{array}{l}0,1253 \\
\pm 0,006\end{array}$ & $\begin{array}{l}0,0928 \\
\pm 0,098\end{array}$ & $\begin{array}{l}0,3193 \\
\pm 0,008\end{array}$ & $\begin{array}{l}0,1315 \\
\pm 0,014\end{array}$ & $\begin{array}{l}0,0506 \\
\pm 0,003\end{array}$ \\
\hline & $\begin{array}{l}\text { Интегральный показа- } \\
\text { тель / Integral indicator }\end{array}$ & 0,1254 & 0,0929 & 0,3209 & 0,13147 & 0,0508 \\
\hline & $\mathrm{t}$ & 13,508 & 0,683 & 30,910 & 1,224 & 5,514 \\
\hline
\end{tabular}


В ходе исследования вычислила средние проявления асимметрии каждого признака, показатель асимметрии для каждого листа, интегральный показатель стабильности развития для каждого места исследования.

Таблица 2 - Общие показатели стабильности развития вяза мелколистного (Ulmus pumila L.) в местах исследования

Table 2 - Common indicators of the stability of the stability of the development of small-leaved Elm (Ulmus pumila L.) in the study sites

\begin{tabular}{|l|c|c|c|}
\hline \multicolumn{1}{|c|}{$\begin{array}{c}\text { Места исследова- } \\
\text { ния / Research sites }\end{array}$} & $\begin{array}{c}\text { Средняя частота проявления асимметрии } \\
\text { на признак / The average frequency of } \\
\text { asymmetries on the basis }\end{array}$ & $\begin{array}{c}\text { Интегральный } \\
\text { показатель / Inte- } \\
\text { gral indicator }\end{array}$ & $\mathrm{t}$ \\
\hline $\begin{array}{l}\text { c. Бузиновка / } \\
\text { s. Buzinovka }\end{array}$ & $0,0329 \pm 0,004$ & 0.033 & \multirow{2}{*}{8.1} \\
\hline $\begin{array}{l}\text { п. Oктябрьский / } \\
\text { p. Oktyabrsky }\end{array}$ & $0,1265 \pm 0,011$ & 0,127 & \\
\hline
\end{tabular}

Сопоставление интегральных показателей с пятибалльной шкалой оценки отклонений состояния организма от условной нормы по величине интегрального показателя асимметрии билатеральных признаков вяза мелколистного (Ulmus pumila L.) двух мест исследования позволило установить достоверные различия (таблица 3 ).

Таблица 3 - Пятибалльная шкала оценки отклонения состояния организма от условной нормы по величине интегрального показателя стабильности развития для Березы повислой (Betula pendula) (по В. М. Захарову, 2000)

Table 3 - A five - point scale for assessing deviations of the state of the body from the conditional norm by the value of the integral indicaton of development stability for the hanging bitch (Betula pendula ) (by V. M. Zaharovu, 2000)

\begin{tabular}{|c|c|}
\hline $\begin{array}{c}\text { Балл / } \\
\text { Score }\end{array}$ & $\begin{array}{c}\text { Величина показателя стабильности развития / } \\
\text { The value of the indicator of development stability }\end{array}$ \\
\hline I & $<0,040$ \\
\hline II & $0,040-0,044$ \\
\hline III & $0,045-0,049$ \\
\hline IV & $0,050-0,054$ \\
\hline V & $>0,054$ \\
\hline
\end{tabular}

Примечание / Note. I балл - условная норма / I score - conditional norm; II балл - слабое влияние неблагоприятных факторов среды / II score - wear influence of adverse environmental; III, IV баллы - загрязненные районы / III, IV scores - polluted areas;

V балл - критическое значение показателя / V score - critical value of the indicator.

Меньший показатель отмечен у вязов с. Бузиновки. У вязов п. Октябрьский интегральный показатель в 3,8 раза выше.

Результаты исследования природной среды методом флуктуирующей асимметрии показывают, что деревья вяза мелколистного (Ulmus pumila L.) испытывают слабое влияние неблагоприятных факторов на территории с. Бузиновки и угнетающее влияние на территории п. Октябрьский.

Выводы. Методом изучения флуктуирующей асимметрии листьев вяза мелколистного (Ulmus pumila L.) установлено, что экологическое состояние природной среды в с. Бузиновка соответствует показателям нормы. Состояние природной среды в п. Октябрьский является критическим, что связано, возможно, с высокой антропогенной нагрузкой.

Библиографический список

1. Ашихмина Т. Я. Разработка методов биологического мониторинга техногенных территорий // Использование и охрана природных ресурсов в России. 2013. № 1. С. 29-35. 
2. Божко Г. Г., Масленникова Л. А., Гончарова Т. А. Наличие флуктуирующей асимметрии и свинца в листьях Березы манджурской // Успехи современного естествознания. 2015. № 9-2. С. 290-292.

3. Зорина А. А. Оценка флуктуирующей асимметрии на основе нормированного отклонения // Принципы экологии. 2013. Т. 2. № 1. С. 69-72.

4. Зорина А. А. Формирование флуктуирующей асимметрии в процессе индивидуального развития Betula pendula // Принципы экологии. 2014. № 4. С. 31-52.

5. Зорина А. А. Техногенная и широтная изменчивость величины асимметрии Березы повислой и пушистой // Проблемы региональной экологии. 2019. № 1. С. 21-29.

6. Зорина А. А. Системное исследование экологического понятия // Современная наука: актуальные проблемы теории и практики. Серия: «Естественные и технические науки». 2019. № 3. C. 31-36.

7. Кабашникова Л. Ф. Прейминг защитных реакций в растениях при патогенезе: приобретённый иммунитет // Журнал Белорусского государственного университета. Экология. 2020. № 4. С. 19-29.

8. Козлов М. В. Исследования флуктуирующей асимметрии растений в России: мифология и методология // Экология. 2017. № 1. С. 3-12.

9. Малащенко В. В., Старшикова Л. В., Гайдученко Е. С. Стабильность развития Betula pendula Roth в урбоэкосистемах Гомельского Поселья // Вестник МДПУ им. И. П. Шамякина. 2013. № 2 (39). C. 19-26.

10. Попельницкая И. М., Попов А. О. Флуктуирующая асимметрия листьев Тополя бальзамического (Populus Balsamifera L) в городской среде // Успехи современного естествознания. 2017. № 12. С. 72-78.

11. Рунова Е. М., Гнаткович П. С. Экологическая оценка рекреационных зон города Братска методом флуктуирующей асимметрии Березы повислой // Фундаметальные науки. 2013. № 11. C. 223-227.

12. Савельева Н. А., Белова Е. Е., Первова Н. Е. Оценка влияния ионов свинца и кадмия на флуктуирующую асимметрию Фасоли обыкновенной (Phaseolus vulgaris L.) // Вестник МГУ. Серия 17: Почвоведение. 2013. № 4. С. 50-52.

13. Собчак Р. О., Афанасьева Т. Г., Копылов М. А. Оценка экологического состояния реакционных зон методом флуктуирующей асимметрии листьев Betula pendula Roth // Вестник Томского государственного университета. 2013. № 368. С. 195-199.

14. Стабильность развития Рябины обыкновенной в условиях Красноярского края / А. Н. Слепов, А. Н. Лагунов, И. С. Коротченко [и др.] // Успехи современного естествознания. 2018. № 12. Ч. 1. С. 104-110.

15. Шушунова Т. Н. Социально-экологические проблемы устойчивого развития // Журнал Белорусского государственного университета. Экология. 2020. - № 1. С. 4-12.

Conclusions. By studying the fluctuating asymmetry of the leaves of the Chinese Elm (Ulmus pumila L.), it was found that the ecological state of the natural environment in the village of Buzinovkacomplies with the norm. The state of the natural environment in the village Oktyabr'skij is critical, which might be due to a high anthropogenic impact.

\section{References}

1. Ashihmina T. Ya. Razrabotka metodov biologicheskogo monitoringa tehnogennyh territorij // Ispol'zovanie i ohrana prirodnyh resursov v Rossii. 2013. № 1. P. 29-35.

2. Bozhko G. G., Maslennikova L. A., Goncharova T. A. Nalichie fluktuiruyuschej asimmetrii i svinca v list'yah Berezy mandzhurskoj // Uspehi sovremennogo estestvoznaniya. 2015. № 9-2. P. 290-292.

3. Zorina A. A. Ocenka fluktuiruyuschej asimmetrii na osnove normirovannogo otkloneniya // Principy jekologii. 2013. V. 2. № 1. P. 69-72.

4. Zorina A. A. Formirovanie fluktuiruyuschej asimmetrii v processe individual'nogo razvitiya Betula pendula // Principy jekologii. 2014. № 4. P. 31-52. 
5. Zorina A. A. Tehnogennaya i shirotnaya izmenchivost' velichiny asimmetrii Berezy povisloj i pushistoj // Problemy regional'noj jekologii. 2019. № 1. P. 21-29.

6. Zorina A. A. Sistemnoe issledovanie jekologicheskogo ponyatiya // Sovremennaya nauka: aktual'nye problemy teorii i praktiki. Seriya: "Estestvennye i tehnicheskie nauki". 2019. № 3. P. 31-36.

7. Kabashnikova L. F. Prejming zaschitnyh reakcij v rasteniyah pri patogeneze: priobretjonnyj immunitet // Zhurnal Belorusskogo gosudarstvennogo universiteta. Jekologiya. 2020. № 4. P. 19-29.

8. Kozlov M. V. Issledovaniya fluktuiruyuschej asimmetrii rastenij v Rossii: mifologiya i metodologiya // Jekologiya. 2017. № 1. P. 3-12.

9. Malaschenko V. V., Starshikova L. V., Gajduchenko E. S. Stabil'nost' razvitiya Betula pendula Roth v urbojekosistemah Gomel'skogo Posel'ya // Vestnik MDPU im. I. P. Shamyakina. 2013. № 2 (39). P. 19-26.

10. Popel'nickaya I. M., Popov A. O. Fluktuiruyuschaya asimmetriya list'ev Topolya bal'zamicheskogo (Populus Balsamifera L) v gorodskoj srede // Uspehi sovremennogo estestvoznaniya. 2017. № 12. P. 72-78.

11. Runova E. M., Gnatkovich P. S. Jekologicheskaya ocenka rekreacionnyh zon goroda Bratska metodom fluktuiruyuschej asimmetrii Berezy povisloj // Fundametal'nye nauki. 2013. № 11. P. 223-227.

12. Savel'eva N. A., Belova E. E., Pervova N. E. Ocenka vliyaniya ionov svinca i kadmiya na fluktuiruyuschuyu asimmetriyu Fasoli obyknovennoj (Phaseolus vulgaris L.) // Vestnik MGU. Seriya 17: Pochvovedenie. 2013. № 4. P. 50-52.

13. Sobchak R. O., Afanas'eva T. G., Kopylov M. A. Ocenka jekologicheskogo sostoyaniya reakcionnyh zon metodom fluktuiruyuschej asimmetrii list'ev Betula pendula Roth // Vestnik Tomskogo gosudarstvennogo universiteta. 2013. № 368. P. 195-199.

14. Stabil'nost' razvitiya Ryabiny obyknovennoj v usloviyah Krasnoyarskogo kraya / A. N. Slepov, A. N. Lagunov, I. S. Korotchenko [i dr.] // Uspehi sovremennogo estestvoznaniya. 2018. № 12. Ch. 1. P. 104-110.

15. Shushunova T. N. Social'no-]kologicheskie problemy ustojchivogo razvitiya // Zhurnal Belorusskogo gosudarstvennogo universiteta. Jekologiya. 2020. - № 1. P. 4-12.

\title{
Author's Information
}

Panchenko Lidiya Sergeevna, a senior lecturer of the Russian language subdepartment of the Department for Training Foreign Specialists, Volgograd State Technical University. 400005, Volgograd, Lenin Avenue, 28. E-mail: q9053959452@yandex.ru, mobile 89053959452.

\section{Информация об авторе.}

Панченко Лидия Сергеевна, старший преподаватель кафедры русского языка факультета подготовки иностранных специалистов Волгоградского государственного технического университета. (400005, г. Волгоград, пр. Ленина, д. 28). E-mail: q9053959452@yandex.ru, т. 89053959452.

\section{ASSESSMENT OF YIELD AND ADAPTABILITY OF LARGE FRUITED TOMATOES WITH DIFFERENT COLORS UNDER THE CONDITIONS OF THE LOWER VOLGA REGION}

\author{
Keegoui Gertrude, S.V. Zaytsev
}

Federal State Budget Scientific Institution

"Caspian Agrarian Federal Scientific Center of the Russian Academy of Sciences», Astrakhan region

Received 27.06.2021

Submitted 20.08.2021

\section{Summary}

The results of comparative evaluation of large fruited tomato varieties and hybrids with different fruits colors during their cultivation in the Lower Volga region are given. Based on the studied research and the obtained experimental material from the varieties and hybrids, the most promising, highly productive and adapted to the conditions of cultivation are distinguished. The results of the study revealed 